\title{
De liefdesverklaring aan een foto-archief over koloniale oorlogsvoering
}

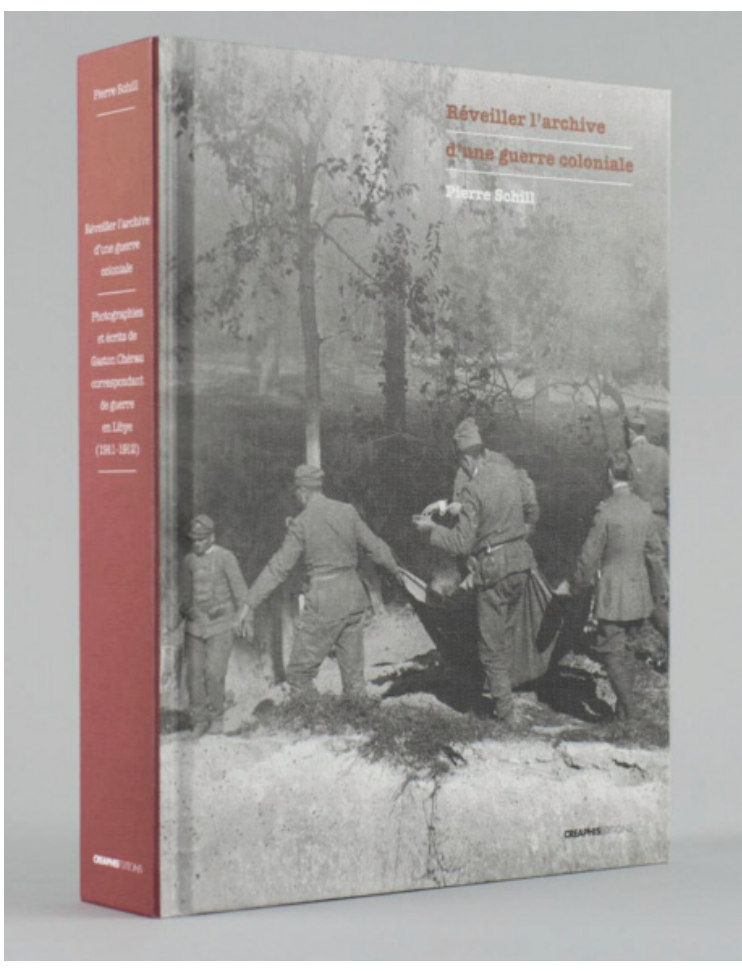

\section{Pierre Schill (ed.)}

Réveiller l'archive d'une guerre coloniale (Grane, Creaphis Éditions, 2018), 482 pp.

isbn 9782354281410

\author{
Reviewed $b y$ \\ Niek Pas is een Nederlandse historicus, als docent \\ verbonden aan de Universiteit van Amsterdam.
}

Een bijzonder boek. Zo kan Réveiller l'archive d'une guerre coloniale gerust worden getypeerd. De kaft van dit fraai vormgegeven werk omarmt twee speciale projecten die het resultaat zijn van toeval, creativiteit en doorzettingsvermogen. De auteur, Pierre Schill, doceert geschiedenis en aardrijkskunde op een middelbare school in Montpellier. Zijn historische belangstelling heeft niets met koloniale geschiedenis van doen; zij geldt de Franse arbeidersbeweging. Maar in 2008, tijdens archiefonderzoek in de collectie van een socialistische afgevaardigde uit de Hérault, stuit Schill op persfoto's van de Italiaans-Turkse oorlog van 1911-1912. Aanvankelijk laat hij de tientallen nietgeklasseerde foto's liggen. Het duurt enkele jaren voordat bij Schill het idee rijpt deze vergeten beelden van de Italiaanse campagne tegen de Ottomanen en de daaropvolgende onderdrukking van Libische opstandelingen op originele manier toegankelijk te maken en daarmee opnieuw tot leven te wekken. 
Het eerste deel van Schills werk is een reconstructie van een uniek foto-archief. Een centrale plek is hierbij ingeruimd voor de fotograaf Gaston Chérau (1872-1937). Chérau, een Franse schrijver die, bij gebrek aan literair succes, zijn carrière een vervolg besluit te geven als foto-journalist. Gewapend met pen en camera steekt hij in het najaar van 1911 de Méditerrannée over om voor de bekende krant $L e$ Matin de Italiaanse opmars in Tripolitanië te verslaan. Het jonge Italiaanse koninkrijk, gedreven door de droom van een nieuw Romeins rijk, strekt begerig zijn handen uit naar het Afrikaanse territorium aan de overkant van Mare Nostrum waar de koloniale krachten van het Ottomaanse rijk aan kracht hebben ingeboet. De botsing tussen de oude en nieuwe koloniale machthebber leidt in 1912 tot een verdrag dat de Italiaanse aanwezigheid in Noord-Afrika bestempelt.

Chérau's uitgebreide geïllustreerde reportages en foto-archief vormen de basis voor Schills reconstructie. Tientallen foto's tonen het dagelijks leven in Tripoli en omgeving en de sleur in het Italiaanse expeditiecorps. Maar Chérau's foto's brengen ook haarscherp de kinderslachtoffers van hongersnood in beeld evenals de gespannen gezichten van soldaten luttele seconden voor een aanval op Turkse linies. Andere series bevatten beelden van berechting en executie van Libische opstandelingen die zich als horzels op de nieuwe machthebbers hebben gestort. Levenloze lichamen aan de galg op een druk marktplein in Tripoli als verstilde gruwelijkheden. Hetzelfde geldt voor de foto's van stoffelijke overschotten van door Turken gemartelde en gekruisigde Italiaanse soldaten.

Schill vult deze fotoschat aan met informatie en fragmenten uit brieven van Chérau aan zijn vrouw. Daarnaast is een gedetailleerd verslag uit 1926 integraal opgenomen. Met deze tekst, 'Sur le trésor des caravanes' genaamd, knoopt Chérau opnieuw aan bij zijn vroegere literaire ambities. De maker, fotograaf en schrijver, staat centraal in deze reconstructie. Dit is in zoverre opmerkelijk omdat in studies over koloniale fotografie doorgaans veel aandacht uitgaat naar slachtoffer-daderdynamiek. Schill ontkent dit spanningsveld niet - hij heeft bijvoorbeeld de namen van geëxecuteerde Libische vrijheidsstrijders achterhaald en op deze wijze naamloze slachtoffers hun identiteit teruggegeven maar hij is toch vooral geïnteresseerd in 'sens de la médiatisation': de manier waarop de koloniale omgeving in al zijn facetten destijds in de openbaarheid kwam en daarnaast ook voor een hedendaags publiek weer toegankelijk - en daarmee: inzichtelijk - kan worden gemaakt. Via Chérau maakt Schill Libië honderd jaar later opnieuw zichtbaar en geeft hij en passant inzicht in de complexiteit van koloniale oorlogsvoering en de dynamiek van de koloniale samenleving; verschillende schaakspelen op één bord.

Een tweede element dat dit werk zo bijzonder maakt is dat Schill op zoek is gegaan naar en ook een manier heeft gevonden om de omgang met en kennis van dat specifieke koloniale verleden algemeen toegankelijk te maken. Deel twee is een kruisbestuiving tussen geschiedkundige en artistieke creatie onder de titel $\grave{A}$ fendre le coeur le 
plus dur. De letterkundige achtergrond van oorlogsfotograaf Chérau heeft hier ongetwijfeld toe aangezet; de titel verwijst namelijk naar een uitspraak van hem in een van zijn brieven aan zijn vrouw over de gruwelijkheden waarmee hij in Libië werd geconfronteerd.

Op verzoek van Schill creëerde choreograaf Emmanuel Eggermont een dansvoorstelling en vervaardigde beeldend kunstenaar Agnès Geoffray sculpturen. Ze maken deel uit van de gelijknamige tentoonstelling die in 2015-2016 in Frankrijk toerde en waarbij ook video's, foto's en audiovisuele installaties van andere contemporaine kunstenaars zijn getoond. Tevens heeft Schill een drietal essays opgenomen over dans, letterkunde, beeldende kunst evenals een afsluitende beschouwing van historicus Quentin Deluermoz. Tenslotte schreven Oliver Rohe en Jérôme Ferrari een literaire tekst - eveneens getiteld À fendre le coeur le plus dur. Ferrari, gelauwerd schrijver en voormalig winnaar van de Prix Goncourt, deed er in 2018 nog een schepje bovenop met $A ̀$ son image, een literaire overdenking van fotografie in koloniale oorlogsvoering. Daarmee is Schills project niets minder dan een Gesammtkunstwerk waarbij vanuit verschillende artistieke gezichtsvelden 'la question du pouvoir et de la puissance des images', destijds en heden ten dage, wordt overdacht.

Op deze creatieve en bijzondere wijze is Schills werk een aanvulling op hedendaagse studies naar fotojournalistiek in koloniën die nogal eens zwichten voor presentisme en postkoloniale theorievorming. Zo legt Paul Bijl, in zijn fraai uitgevoerde proefschrift Emerging Memory (2015), expliciet een link tussen foto's van koloniale excessen en de wording van Nederlandse herinneringscultuur. De aan de Universiteit Utrecht verbonden Bijl analyseert het koloniale verleden vanuit de kruisbestuiving van postcolonial studies, visual culture en cultural memory studies maar richt zich uitsluitend op geweldsfoto's, hoe dezen door de decennia heen zijn geframed en nu eens opduiken en dan weer onderduiken in het maatschappelijke verkeer. Schills benadering biedt meer ruimte voor perspectiefwisselingen. Het is misschien wat vlot geconcludeerd maar misschien ontwaren we de contouren van zoiets als een Franse stroming want Schills landgenoot Daniel Foliard getuigt van eenzelfde brede blik. De aan Université ParisNanterre verbonden fotohistoricus toont zich in Combattre, punir, photographier. Empires coloniaux, 1890-1914 (2020) uitermate kritisch over wat hij 'positivisme documentaire' noemt. Foliard verstaat daaronder radicale academische stromingen die een overwegend binaire kijk huldigen op de koloniale maatschappij, een omgeving van schuld en boete, (letterlijk) zwartwit. Foliard is niet geïnteresseerd in eenzijdige schuldvragen, 'culpabilité,' 'déni' of 'martyrologie'. Zijn interesse is gebaseerd op de rijkdom en reikwijdte van fotografie in koloniale context. Evenals Nicholas Mirzoeff in diens befaamde The Right to Look (2011) benadrukt hij de wederkerigheid in fotografie - het koloniale subject was niet machteloos maar kéék terug en beschikte op verschillende manieren over agency. 
Foliard staat bijvoorbeeld uitgebreid stil bij inheemse fotografen, Ottomaanse en Japanse koloniale fotografie en pleit ervoor de klassieke centrum-periferie, vanuit Europa naar de koloniën, te verruimen voor een gedifferentieerde analyse vanuit verschillende gezichtspunten en geografische omgevingen. Een dergelijke pluriforme, de vakdisciplines overstijgende, open en bevragende benadering treffen we ook aan bij Schill. Diens Libië-werk is niets minder dan een tour de force op het snijvlak van ambacht en artisticiteit, kunde en kunst. Schill heeft Chérau's fotoarchief over koloniale oorlogsvoering op sublieme wijze tot leven gewekt: met een kus. 


\section{TMG Journal for Media History}

Volume 24 No $(1 / 2) / 2021$

\section{DOI}

https://dx.doi.org/10.18146/tmg.798

\section{PUBLISHER}

Netherlands Institute for Sound and Vision

\section{COPYRIGHT}

Each article is copyrighted (c) by its author(s) and is published under license from the author(s). When a paper is accepted for publication, authors will be requested to agree with the Creative Commons Attribution 4.0 International License. 